\title{
Hippopotamus and livestock grazing: influences on riparian vegetation and facilitation of other herbivores in the Mara Region of Kenya
}

\author{
Erustus M. Kanga $\cdot$ Joseph O. Ogutu • \\ Hans-Peter Piepho $\cdot$ Han Olff
}

Received: 9 December 2010/Revised: 30 June 2011/ Accepted: 9 July 2011/Published online: 19 August 2011

(C) The Author(s) 2011. This article is published with open access at Springerlink.com

\begin{abstract}
Riparian savanna habitats grazed by hippopotamus or livestock experience seasonal ecological stresses through the depletion of herbaceous vegetation, and are often points of contacts and conflicts between herbivores, humans and their livestock. We investigated how hippopotamus and livestock grazing influence vegetation structure and cover and facilitate other wild herbivores in the Mara region of Kenya. We used $5 \mathrm{~km}$-long transects, each with 13 plots measuring $10 \times 10 \mathrm{~m}^{2}$, and which radiate from rivers in the Masai Mara National Reserve and adjoining community pastoral ranches. For each plot, we measured the height and visually estimated the percent cover of grasses, forbs, shrubs and bare ground, herbivore abundance and species richness. Our results showed that grass height was shortest closest to rivers in both landscapes, increased with increasing distance from rivers in the reserve, but was uniformly short in the pastoral ranches. Shifting mosaics of short grass lawns interspersed with patches of medium to tall grasses occurred within $2.5 \mathrm{~km}$ of the rivers
\end{abstract}

E. M. Kanga $(\bowtie)$

Kenya Wildlife Service, P. O. Box 40241, Nairobi, Kenya

e-mail: ekanga@kws.go.ke

E. M. Kanga $\cdot$ H. Olff

COCON-CEES, University of Groningen,

Centre for Life Sciences, Postbox 11103,

9700 CC Groningen, The Netherlands

J. O. Ogutu · H.-P. Piepho

Universitaet Hohenheim, Institute of Crop Science,

Fruwirthstrasse 23, 70599 Stuttgart, Germany

J. O. Ogutu

International Livestock Research Institute,

Old Naivasha Road, P. O. Box 30709, Nairobi, Kenya in the reserve in areas grazed habitually by hippos. Hence, hippo grazing enhanced the structural heterogeneity of vegetation but livestock grazing had a homogenizing effect in the pastoral ranches. The distribution of biomass and the species richness of other ungulates with distance from rivers followed a quadratic pattern in the reserve, suggesting that hippopotamus grazing attracted more herbivores to the vegetation patches at intermediate distances from rivers in the reserve. However, the distribution of biomass and the species richness of other ungulates followed a linear pattern in the pastoral ranches, implying that herbivores avoided areas grazed heavily by livestock in the pastoral ranches, especially near rivers.

Keywords Grazing lawn - Landscape · Piosphere . Spatial heterogeneity

\section{Introduction}

African savannas support a diverse indigenous herbivore assemblage besides livestock production by pastoral communities (Skarpe 1991). Understanding the spatial and temporal dynamics of savannas used by wild herbivores, livestock and people is essential for their effective management for wildlife conservation and to promote human well-being (Coughenour 1991; Bailey et al. 1996). The distribution of herbivores within landscapes is influenced by the composite effects of biotic factors such as competition, species composition, forage quality and quantity, and abiotic factors such as topography and distance to water (Milchunas and Laurenroth 1993; Bailey et al. 1996; Illius and O'Connor 2000; Adler et al. 2001; Landsberg et al. 2003; Redfern et al. 2003). In particular, the distribution of herbivores in arid and semi-arid savannas is 
strongly influenced by the location of surface water and nutritious forage, especially during the dry season, when water becomes progressively limiting and water sources become points of contact and conflict between herbivores, humans and their livestock (Western 1975; Fryxell and Sinclair 1988; Illius and O'Connor 2000).

Forage production in savannahs is primarily limited by rainfall, which varies considerably in space and time, producing patchiness in green forage and ephemeral water availability (Deshmukh 1984; Boutton et al. 1988). However, African herbivores have adapted to the seasonal variability in forage and water by performing regular seasonal migrations or irregular and unpredictable dispersal movements between water and forage resources (Fryxell and Sinclair 1988; Fryxell et al. 1988). Furthermore, herbivore distribution patterns in response to resource variability reflect trade-offs between satisfying their water and forage requirements and minimizing predation risk (Bergman et al. 2001; Bailey et al. 1996). Herbivore functional groupings based on body size, dietary guild, foraging behavior and digestive physiology may further explain variations in the patterns of their distributions (Jarman 1974; Demment and Vansoet 1985; Wilmshurst et al. 2000). Thus, among the more water-dependent herbivores, large-sized animals should travel further distances from water sources than small animals to satisfy their forage quantity requirements. The less water-dependent herbivores such as browsers are less constrained by distance to water sources (Western 1975; Redfern et al. 2003). Nevertheless, during dry seasons, more rapid depletion of forage occurs near water sources.

At the landscape scale, radial gradients in vegetation characteristics originating from areas of concentrated resource use provide evidence for how herbivores influence vegetation patterns. The impact of herbivore grazing in savannas is greater closer to water points, creating utilization gradients termed piospheres (Lange 1969; Andrew 1988; Thrash 1998, 2000; Thrash and Derry 1999). However, relatively little is known about the development of piosphere gradients in ecosystems supporting diverse assemblages of large wild herbivores, livestock and pastoralists, such as the semi-arid savanna ecosystems of East Africa. Riparian savanna habitats in such ecosystems, if also grazed heavily by hippopotamus (Hippopotamus amphibious, Linnaeus 1758) or livestock, may experience seasonal ecological stresses through the depletion of herbaceous vegetation and increased denudation (Thornton 1971; Lock 1972; Fleischner 1994; Eltringham 1999; Oba et al. 2000). While most wild herbivores are highly mobile and distribute their grazing impacts more evenly over the landscape, hippos and pastoral livestock are typically central-place foragers, because hippos must leave and return to water, whereas pastoral livestock must leave and return to pastoral settlements daily. This creates zones of attenuating impacts from water and settlements (Ogutu et al. 2010), which, in turn, affect the use of riparian habitats and pastoral landscapes by other herbivores. Hippo grazing can be potentially destructive to vegetation due to a combination of their large daily food requirements and their characteristic grazing style of plucking grass (Lock 1972; Eltrigham 1974; Thornton 1971). Similarly, heavy livestock grazing can be detrimental to wildlife habitats (Jones 1981; Quinn and Walgenbach 1990; Fleischner 1994), except under well-managed grazing conditions (Vavra 2005). Fleischner (1994) underscored this point by asserting that the ecological costs of livestock grazing include the general loss of biodiversity, manifested in reduced population densities of a wide variety of taxa, as well as aiding the spread of alien and weedy species; disrupting ecosystem functions, including nutrient cycling and succession; changes in community organization and vegetation stratification; and damage to soils.

Hippos not only pluck grass but they also create and maintain short grass lawns in areas where they preferentially feed (Olivier and Laurie 1974; Eltringham 1999; Arsenault and Owen-Smith 2002). The mosaics of closely cropped grass lawns interspersed with areas of long grass alter the vertical vegetation structure and create patchy landscapes of varying vegetation height and cover. This increases spatial heterogeneity in vegetation structure (Hobbs 1996; Adler et al. 2001), which is important to other wildlife through its indirect effects on competition, facilitation and predator-prey relationships (Prins and Olff 1998; Murray and Illius 2000). The enhanced structural diversity of vegetation patches can facilitate other herbivores that differentially select vegetation patches with intermediate biomass and high-quality forage (Wilmshurst et al. 2000; Prins and Olff 1998; Olff et al. 2002; Arsenault and Owen-Smith 2002), and avoid patches with higher predation risk, such as tall grasslands and other potential predator ambush sites (Hernandez and Laundre 2005; Verdolin 2006). In contrast, relatively few systematic investigations have found positive benefits of livestock grazing for other wild herbivores (Belsky et al. 1999). As such, the effects of livestock grazing on wildlife populations are an important conservation concern (Fleischner 1994; Prins 2000).

In recent decades, human-induced land-use changes, excessive resource extraction, and the erection of artificial barriers have increasingly threatened savanna ecosystems by reducing grazing areas and disrupting access to water sources. Consequently, declining savanna rangelands and sedentarization of pastoralists (Kimani and Pickard 1998; Homewood et al. 2001; Lamprey and Reid 2004; Western et al. 2009) as well as the associated expansion of 
settlements and the cultivation and intensification of livestock grazing could fundamentally modify the spatial distributions and movement patterns of herbivores and heighten competition between livestock and wildlife (Prins and Olff 1998). This could accelerate the degradation and fragmentation of rangelands and cause declines in wild herbivore populations (Verlinden 1997; Serneels et al. 2001). If such savannah habitats are utilized by both hippos and livestock, they may be expected to compete for limiting grazing resources, especially close to water points. Furthermore, because hippo and livestock grazing can differentially modify vegetation structure, they may have contrasting effects on the species richness, abundances and distributions of other wildlife species, especially during dry seasons, when most large herbivores are concentrated within $5 \mathrm{~km}$ of water in semi-arid savannas (Western 1975; Redfern et al. 2003). Our limited current understanding of these processes support the need for investigations that encompass both protected and pastoral systems and elucidate how hippo and livestock grazing modify the structure of riparian-edge habitats and their utilization by other wild ungulates in savannas.

We investigated the effects of hippopotamus and livestock grazing along a riparian habitat in the Masai Mara region of Kenya in order to address the following two overarching questions. (1) How does hippo and livestock grazing modify vegetation structure and cover as a function of distance from rivers in semi-arid savannas? (2) How does the impact of hippo and livestock grazing on vegetation as a function of distance from water influence the distribution of biomass and the species richness of the other wild ungulates? We expected hippo and livestock grazing activities to have contrasting effects on vegetation structure and cover based on differences in their grazing strategies: hippos pluck grasses and create and maintain short grass lawns, while livestock are bulk grazers and frequently uproot shallow-rooted grasses. We also hypothesized that if the intensity of grazing declines with increasing distance from water sources, then vegetation height and basal cover will increase with distance from the water in both hippoand livestock-dominated landscapes. Since hippos create and maintain mosaics of short grass lawns intermixed with medium to tall grasses, and livestock grazing creates uniformly short grasslands, hippo-dominated areas will be more spatially heterogeneous and attract a more diverse array and an abundance of other wild herbivore species close to water, but wild herbivores will tend to avoid areas near the water in livestock-dominated areas. Tests of these hypotheses are essential for predicting the long-term effects of sedentarization of pastoralists and the associated intensification of land use and competition between livestock and herbivores around water sources due to declining forage resources.

\section{Methods}

Study area

The Mara region (Mara) is located in southwestern Kenya, between latitudes $34^{\circ} 45^{\prime} \mathrm{E}$ and $36^{\circ} 00^{\prime} \mathrm{E}$, and is bounded by the Serengeti National Park (SNP) in Tanzania to the south and Siria escarpment to the west (Fig. 1). This region forms the northernmost limit of the Serengeti-Mara ecosystem, covering some $25,000 \mathrm{~km}^{2}$ and straddling the Kenya-Tanzania boundary. The ecosystem comprises several wildlife conservation administrations and conservation-pastoralist multiple land use zones in each of the two countries (Sinclair and Arcese 1995). The Mara covers about 5,500 $\mathrm{km}^{2}$, with the Masai Mara National Reserve (MMNR) covering some $1,530 \mathrm{~km}^{2}$, while the adjacent pastoral ranches, including Koyiaki $\left(931 \mathrm{~km}^{2}\right)$, Olkinyei $\left(787 \mathrm{~km}^{2}\right)$, Siana $\left(1,316 \mathrm{~km}^{2}\right)$, Lemek $\left(717 \mathrm{~km}^{2}\right)$, and $\mathrm{Ol}$ Chorro Oiroua $\left(59 \mathrm{~km}^{2}\right)$, cover a combined total of about $4,000 \mathrm{~km}^{2}$. The Mara receives an annual rainfall of about $877 \mathrm{~mm}$ in the southeast, rising to $1341 \mathrm{~mm}$ at the northwestern edge (Ogutu et al. 2011). Rainfall is bimodal, with the short rains falling from November to December and the long rains from January to June, though January and February are often dry. The vegetation is predominantly grassland, with isolated scrublands and woodlands, especially along the drainage lines and on hill tops (Epp and Agatsiva 1980).

Several rivers and numerous streams drain the Mara, with the Mara River being the only permanent river. The Sand, Talek and Olare-Orok rivers, the main tributaries of the Mara River, are largely seasonal. The Mara River is about $396 \mathrm{~km}$ long and its flow through the MMNR and SNP sustains a wide variety of abundant herbivore species, 10 of which form the main focus of this study, and include the hippopotamus (Hippopotamus amphibious, Linnaeus 1758), wildebeest (Connochaetes taurinus Burchell, 1823), Burchell's zebra (Equus burchelli Gray 1824), the African buffalo (Syncerus caffer, Sparrman 1779), topi (Damaliscus korrigum, Ogilby 1837), Coke's hartebeest (Alcelaphus buselaphus, Gunther 1884), Grant's gazelle (Gazella granti, Brooke 1872), Thomson's gazelle (Gazella thomsoni, Günther 1884), warthog (Phacochoerus aethiopicus, Gmelin 1788) and impala (Aepyceros melampus, Lichtenstein 1812). Populations of these herbivore species face water-related constraints in the Mara in the dry season, including increasing water shortages and declining water quality linked to expanding irrigated cultivation, unregulated water extractions and deforestation of the Mau Forest catchments of the Mara River (Mati et al. 2008).

Marked declines in herbivore numbers in the Mara have been attributed to their progressive exclusion from the pastoral ranches by land-use changes, including expanding 
Fig. 1 Map of Masai Mara National Reserve and the adjoining pastoral ranches showing the transects (numbered), radiating from rivers, that were sampled during 2007-2008. The four study sites were the protected Masai Mara National Reserve $\left(1,530 \mathrm{~km}^{2}\right)$ and the Koyiaki $\left(931 \mathrm{~km}^{2}\right)$, Lemek $\left(717 \mathrm{~km}^{2}\right)$ and $\mathrm{Ol}$ Chorro Oiroua $\left(59 \mathrm{~km}^{2}\right)$ pastoral ranches

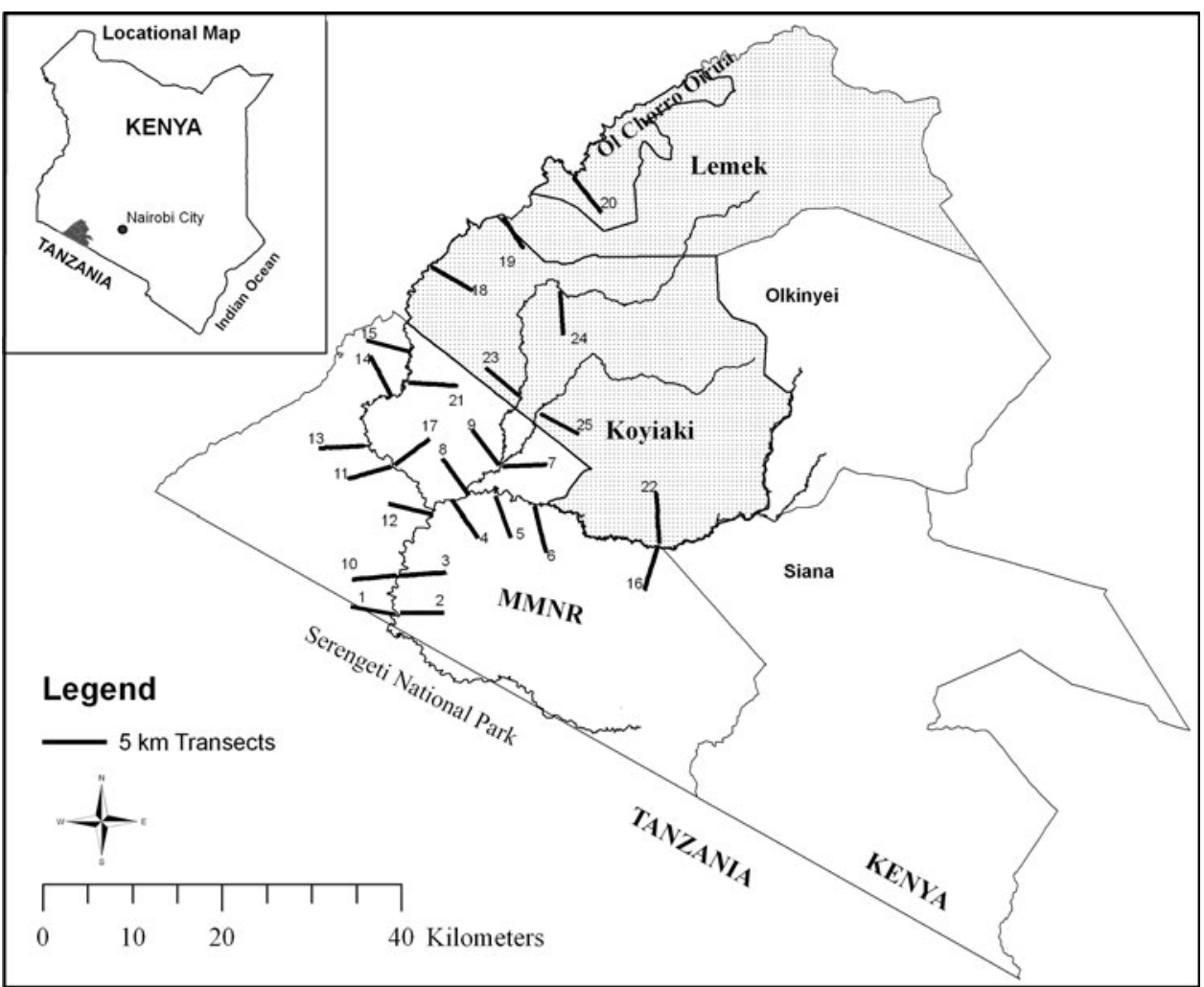

mechanized and subsistence agriculture and settlements, which have affected over $8 \%$ of the Mara and caused landcover changes in at least $36 \%$ of the pastoral ranches adjoining the MMNR (Homewood et al. 2001; Lamprey and Reid 2004; Mati et al. 2008). These changes have intensified competition between livestock and wild herbivores in the pastoral ranches of the Mara. Moreover, sedentarization of the formerly semi-nomadic Maasai pastoralists (Kimani and Pickard 1998; Western et al. 2009) and the associated intensification of land use and grazing by large numbers of livestock in the pastoral ranches accelerate range degradation and fragmentation, including along riparian habitats. Rising temperatures and recurrent droughts (Ogutu et al. 2007) have further amplified herbivore mortalities in the Serengeti-Mara ecosystem.

\section{Sampling design}

We selected two landscapes: a protected conservation reserve, the Masai Mara National Reserve, and the adjoining community pastoral ranches of Koyiaki, Lemek and $\mathrm{Ol}$ Chorro Oiroua (Fig. 1). Livestock grazing is prohibited in the reserve except for illegal incursions, but livestock and wildlife graze together in the pastoral ranches. We established 25 random transects, each $5 \mathrm{~km}$ long and radiating from the Mara, Talek and Olare Orok Rivers. Sixteen transects were located in areas grazed by hippopotamus and other wild herbivores, while another nine transects were placed in areas grazed by livestock, hippos and other wild herbivores (Fig. 1). However, along the $5 \mathrm{~km}$ riparian strip, hippos and livestock are the main resident grazers in the MMNR and the pastoral ranches, respectively. Topography increased rather gently away from rivers within the $5 \mathrm{~km}$ distance sampled by transects in both the reserve (range 1,668-1,718 m) and the pastoral ranches $(1,773-1,836 \mathrm{~m})$, and hence probably did not strongly affect vegetation structure. However, the effects of variation in topography with distance from water, if any, would be confounded with those of distance from water because transects radiated away from rivers and topography increased away from rivers in the same manner as distance.

Along each transect, we established 13 sampling plots, each measuring $10 \times 10 \mathrm{~m}^{2}$, at distances of $0,100,250$, 500, 750, 1,000, 1,250, 1,500, 2,000, 2,500, 3,000, 4,000 and $5,000 \mathrm{~m}$ from rivers. In each plot, we visually estimated the percent cover of three growth forms of vegetation (grasses, forbs and shrubs) and bare ground. Grasses were further subdivided into three height classes: less than $10 \mathrm{~cm}$ tall, 10-30 cm, and greater than $30 \mathrm{~cm}$. The cover measurements provided a simple, quick and efficient method for assessing rangeland conditions. To estimate how herbivores other than hippo and livestock utilized the landscape, we counted all herbivore dung or pellet piles in each plot. Dung and pellet counts are likely reliable as 
relative measures of habitat use by herbivores because none of the herbivore species we studied is strictly territorial. Additionally, we enumerated all herbivores sighted within $200 \mathrm{~m}$ on either side of each plot. To indicate how herbivores utilize the rangelands in space and time, the herbivore counts were converted to biomass using the unit weights in Coe et al. (1976). Further, we assessed herbivore predation risk by estimating the percentage visibility of a predator concealed in vegetation at a distance of $30 \mathrm{~m}$ from the center of each plot along $0^{\circ}, 90^{\circ}, 180^{\circ}$ and $270^{\circ}$ bearings using the method of Hopcraft (2002). Finally, because hippos have been shown to create and maintain mosaics of short-grass lawns, we counted all hippopotamus trails within a $50 \mathrm{~m}$ radius from the center of each plot. Field samplings were carried out during the early dry (July-August) and late dry (September-October) seasons of 2007 and 2008 and in the late wet season (March-April) of 2008. We were unable to access the study area to obtain samples for the early wet (January-February) season of 2008 as scheduled due to the outbreak of widespread postelection violence in Kenya at the time. Transects were treated as the unit of replication. The total of 650 samples ( $n=325$ plots $\times 2$ seasons) dropped to 636 as 14 samples ( $n=8$ for the reserve and $n=6$ for the ranches) were discarded because the associated plots were either burned in the dry season or were inaccessible in the wet season due to heavy rainfall. The 16 transects used in the reserve therefore produced 406 samples during the wet and dry seasons combined, whereas the nine transects used in the pastoral ranches produced 230 samples over the same period.

\section{Data analysis}

We used a multivariate generalized linear model to relate the proportions of vegetation cover in different growth forms and bare ground and the number of hippo trails to distance from water, landscape, season and their interactions, assuming a binomial error distribution and a logit link function (Ruppert et al. 2003). We used a multivariate test of significance to evaluate the significance of the relationships between the number of hippo trails and the proportions of grass cover and bare ground. Further, we used a generalized linear model with a log-normal error distribution and the identity link function to relate aggregate herbivore biomass, dung piles and species richness to distance from water, landscapes, seasons and their interactions. Finally, we used a multiple linear regression to relate vegetation structure to predation risk and herbivore biomass. Herbivore counts were converted to biomass, aggregated over all species, and log-transformed, whereas the percentage cover of vegetation was arcsine square-root transformed prior to analyses. We performed residual and influence diagnostics to evaluate the goodness-of-fit of the selected models, and examined plots of distributions of residuals against the linear predictors, $Q-Q$ plots of the normal distribution, box-whisker plots of residuals, and frequency histograms of residuals to detect outliers or departure from normality. Preliminary analyses showed no significant differences in the distribution patterns away from rivers for the early dry (July-August) and late dry (September-October) season samples within either 2007 or 2008, or between both years. Therefore, we averaged (pooled) the early and late dry season samples of 2007 and 2008 to obtain one dry season sample for both years, which we compared with the late wet season (April-May) sample of 2008 in the analyses. All models were fitted in Statistica version 8 (StatSoft 2007) and in the SAS GLIMMIX procedure (SAS Institute 2009).

\section{Results}

Distribution of hippo trails from water

The mean number of hippo trails was significantly higher $\left(F_{1,584}=36.9, P<0.001\right)$ in the MMNR $(0.31 \pm 0.02$, $n=406$ samples) than in the pastoral ranches $(0.13 \pm$ $0.02, n=230)$. Hippo trails declined significantly with distance from rivers $\left(F_{12,584}=10.8, P<0.001\right)$, and this pattern was similar in both landscapes $\left(F_{12,584}=1.5\right.$, $P=0.147$; Fig. 2). During the wet season, hippos actively utilized a strip within $2.5 \mathrm{~km}$ of the rivers on either side in both landscapes, but extended this to $3 \mathrm{~km}$ in the pastoral ranches and $4 \mathrm{~km}$ in the MMNR during the dry season.

\section{Distributions of vegetation cover from water}

The mean percentage cover of the five components of vegetation differed significantly across seasons $\left(F_{6,589}=\right.$ 12.6, $P<0.001)$, landscapes $\left(F_{6,589}=19.5, P<0.001\right)$, and with distance from water $\left(F_{72,3210}=3.9, P<0.001\right.$, Fig. 3; Table 1). The mean percentage cover of bare ground was similar in both seasons and landscapes, but declined significantly with increasing distance from water $(P<0.001)$, and the pattern of this decline varied between landscapes $(P<0.001)$ such that the percent cover of bare ground was lower in the pastoral ranches than in the MMNR within $500 \mathrm{~m}$ from rivers but became higher in the ranches than the reserve at greater distances from rivers (Fig. 3a). The mean percentage cover for grasses shorter than $10 \mathrm{~cm}$ was higher in the dry $(0.85 \pm 0.03, n=313)$ than the wet $(0.64 \pm 0.03, n=323, P<0.001)$ season, in the pastoral ranches $(0.92 \pm 0.03, n=230)$ than in the MMNR $(0.57 \pm 0.02, n=406, P<0.001)$, and declined significantly with increasing distance from rivers 


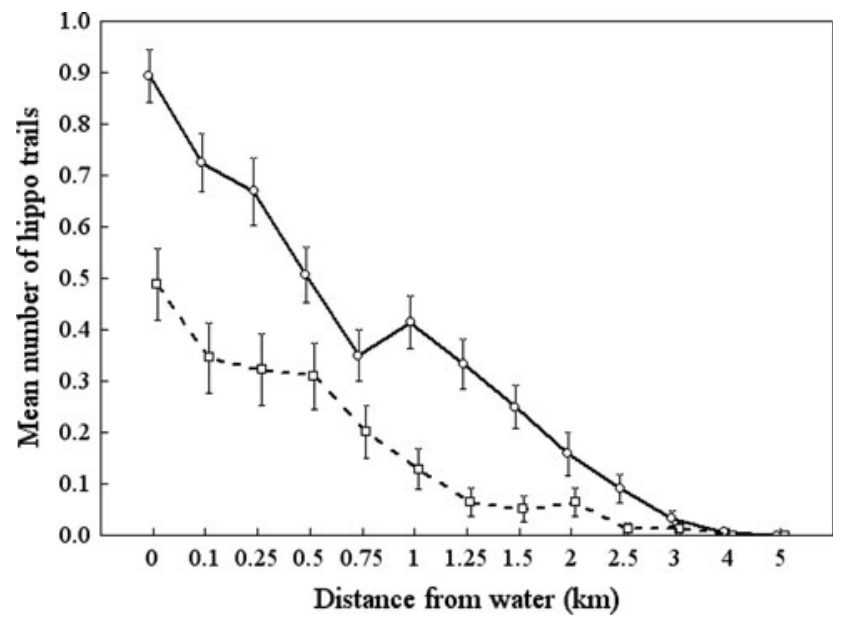

Fig. 2 Mean number of hippopotamus trails as a function of distance from water in the Mara region of Kenya during 2007-2008. Solid and dashed lines denote the Masai Mara National Reserve and pastoral ranches, respectively

$(P=0.009)$. The declines with distance were significant for the MMNR but not for the pastoral ranches (Fig. 3c). The mean percentage cover of grasses $10-30 \mathrm{~cm}$ tall was similar in both seasons, but was marginally higher in the MMNR $(0.28 \pm 0.02, n=406)$ than in the pastoral ranches $(0.23 \pm 0.02, n=230, P=0.072)$. For the reserve, the percent cover of grasses in the $10-30 \mathrm{~cm}$ height class first increased up to $1.25 \mathrm{~km}$ from water and then declined with a further increase in distance from rivers. For the ranches, the corresponding percent cover increased with distance from the river up to $0.75 \mathrm{~km}$, declined between 0.75 and $2 \mathrm{~km}$, and increased thereafter (Fig. 3e).

The mean percentage cover for grasses taller than $30 \mathrm{~cm}$ was higher in the wet $(0.54 \pm 0.03, n=323)$ than the dry $(0.28 \pm 0.03, n=313, P<0.001)$ season, in the MMNR $(0.58 \pm 0.03, n=406)$ than in the pastoral ranches $(0.25 \pm 0.03, n=230, P<0.001)$, and increased significantly away from rivers. The increase was steeper in the MMNR than the pastoral ranches at a distance of $>0.5 \mathrm{~km}$ from the water $(P=0.001$, Fig. $3 b)$. The mean percentage cover of forbs was higher in the wet $(0.14 \pm 0.01$, $n=323)$ than the dry $(0.11 \pm 0.01, n=313, P=0.007)$ season, similar in both landscapes, but first increased with increasing distance from the water and then declined steadily thereafter in both landscapes $(P<0.001$, Fig. $3 \mathrm{~d})$. For shrubs, the mean percentage cover was similar in the dry and wet seasons but higher in the pastoral ranches $(0.06 \pm 0.01, n=230)$ than in the MMNR $(0.04 \pm 0.00$, $n=406, P=0.009)$, but it declined similarly with distance from water in both landscapes $(P<0.001$, Table 1 ; Fig. 3f). A multivariate test of significance showed that there were significant relationships between hippo trails and percent cover of bare ground and grasses (Wilks' lambda $=0.81 ; F_{6,627}=12.4, P<0.001$ ), such that the cover of bare ground $(P<0.001)$, forbs $(P<0.001)$ and grasses shorter than $10 \mathrm{~cm}(P=0.002)$ increased significantly with increasing number of hippopotamus trails, whereas the cover of grasses taller than $30 \mathrm{~cm}(P=0.001)$ declined with increasing number of trails.

Herbivore dung piles, biomass and species richness

The mean number of dung piles per plot was significantly higher in the dry $(1.28 \pm 0.12, n=313)$ than the wet $(0.39 \pm 0.11, n=323$, Table 2$)$ season, reflecting the influx of the migratory herbivores in the dry season. There were more dung piles per plot in the MMNR $(1.07 \pm 0.10$, $n=406)$ than the pastoral ranches $(0.60 \pm 0.13, n=230)$ but this pattern varied seasonally such that in the dry season the MMNR had more dung piles per plot $(1.69 \pm 0.22$, $n=199)$ than the pastoral ranches $(0.84 \pm 0.19, n=114)$, whereas in the wet season the numbers of dung piles were similar between the MMNR $(0.42 \pm 0.06, n=207)$ and the pastoral ranches $(0.37 \pm 0.08, n=116)$.

The total herbivore biomass was significantly higher in the dry $(3.79 \pm 0.25, n=313)$ than the wet $(2.04 \pm 0.24$, $n=323$; Table 3) season. The MMNR had more herbivore biomass $(3.46 \pm 0.21, n=406)$ than the pastoral ranches $(2.38 \pm 0.28, n=230)$, and biomass increased significantly and linearly with distance from water in the ranches (Fig. 4). In the MMNR, by contrast, the total herbivore biomass increased with distance from water up to $0.5 \mathrm{~km}$, declined between 0.5 and $2 \mathrm{~km}$ from water, and then increased thereafter (Fig. 4).

Herbivore species richness was significantly higher during the dry $(1.05 \pm 0.02, n=313)$ than the wet $(0.87 \pm 0.23, n=323)$ season, and was higher in the MMNR $(1.00 \pm 0.02, n=406)$ than in the pastoral ranches $(0.93 \pm 0.02, n=230$, Table 4$)$. The number of herbivore species increased significantly with distance from water in the dry season, but in the wet season the number of species did not show a consistent pattern of variation with distance from water. The number of species increased significantly and linearly with distance from water in the ranches, but in the reserve it increased between 0 and $0.5 \mathrm{~km}$, declined between 0.5 and $1.5 \mathrm{~km}$, and then increased thereafter (Fig. 5).

Relationship between vegetation structure, predation risk, and herbivore biomass

Multiple linear regression analysis showed that predation risk was negatively correlated with the percentage cover of grasses shorter than $10 \mathrm{~cm}\left(t_{632}=-3.18 ; P=0.001\right)$ and between 10 and $30 \mathrm{~cm}$ tall $\left(t_{632}=-3.22 ; P=0.001\right)$, but positively correlated with the percentage cover of grasses taller than $30 \mathrm{~cm}\left(t_{632}=2.52 ; P=0.011\right)$. Multiple linear 

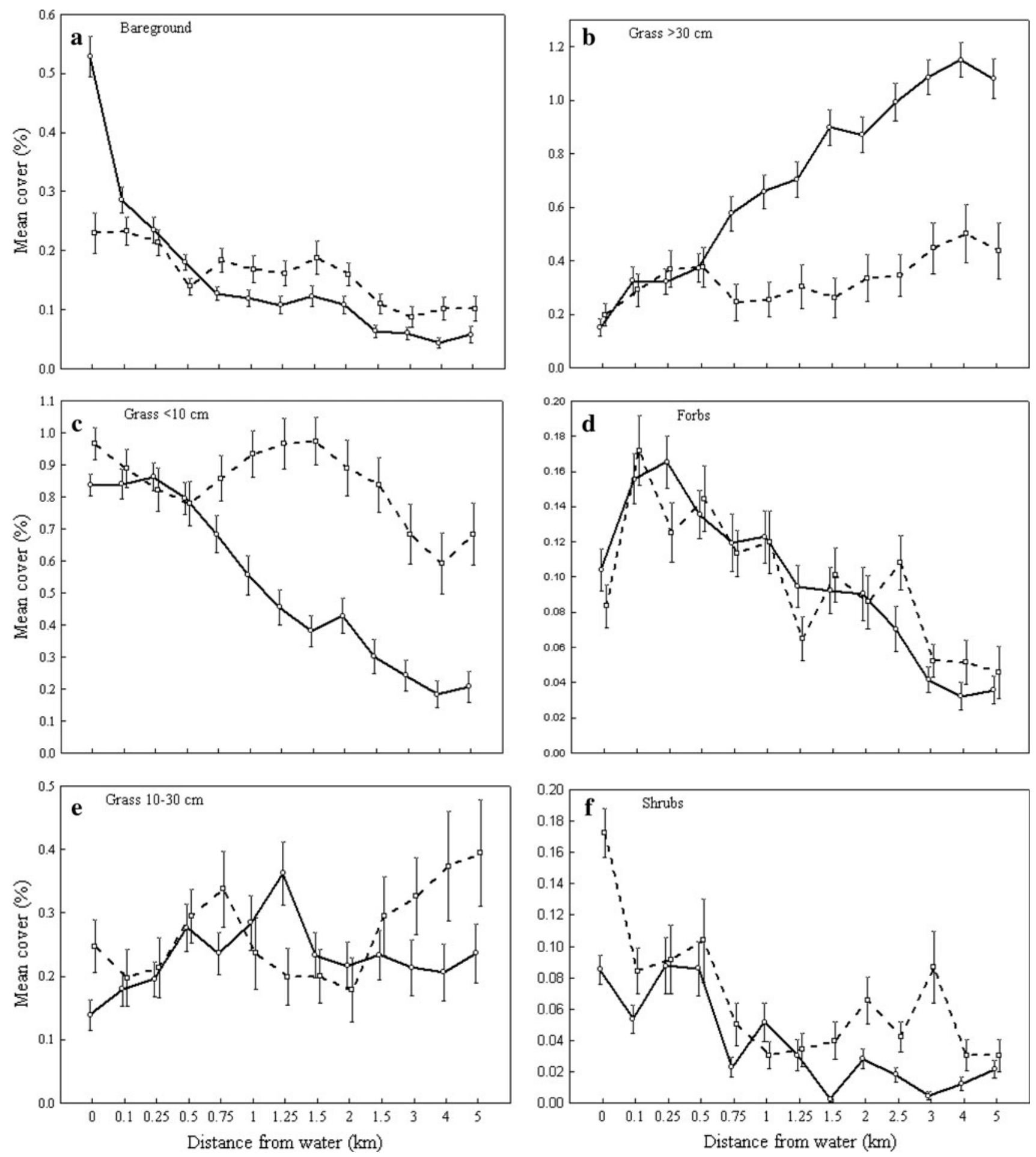

Fig. 3 Mean percent cover of vegetation and bare soil and interactions between landscape and distance from water in the Mara region of Kenya during 2007-2008. Solid and dashed lines denote the Masai Mara National Reserve and pastoral ranches, respectively

regression analysis also showed that herbivore biomass was negatively correlated with predation risk $\left(t_{634}=-6.09\right.$; $P<0.001$ ), such that herbivore biomass declined as predation risk increased, implying that herbivores avoided areas dominated by grasses taller than $30 \mathrm{~cm}$.

\section{Discussion}

Hippopotamus and livestock grazing in the Mara influence the structural patterns of vegetation as a function of distance from rivers. Other herbivores attracted to areas close to 
Table 1 Results of statistical tests of the effects of season, landscape, distance from water, and their interactions on the mean percentage cover of bare ground, grass and shrubs in the Mara region of Kenya
$N D F$ is the degrees of freedom of the numerator and $D D F$ is degrees of freedom of the denominator

\begin{tabular}{|c|c|c|c|c|c|}
\hline Variable & Effect & NDF & DDF & $F$ & $P>F$ \\
\hline \multirow[t]{7}{*}{ Bare ground } & Intercept & 1 & 594 & 805.5 & $<0.001$ \\
\hline & Season & 1 & 594 & 1.6 & 0.209 \\
\hline & Landscape & 1 & 594 & 2.0 & 0.154 \\
\hline & Distance & 12 & 594 & 11.9 & $<0.001$ \\
\hline & Season $\times$ landscape & 1 & 594 & 0.9 & 0.345 \\
\hline & Season $\times$ distance & 12 & 594 & 0.4 & 0.968 \\
\hline & Landscape $\times$ distance & 12 & 594 & 5.3 & $<0.001$ \\
\hline \multirow[t]{7}{*}{ Grass $<10 \mathrm{~cm}$} & Intercept & 1 & 594 & $1,589.8$ & $<0.001$ \\
\hline & Season & 1 & 594 & 29.5 & $<0.001$ \\
\hline & Landscape & 1 & 594 & 87.1 & $<0.001$ \\
\hline & Distance & 12 & 594 & 4.6 & $<0.001$ \\
\hline & Season $\times$ landscape & 1 & 594 & 0.3 & 0.617 \\
\hline & Season $\times$ distance & 12 & 594 & 0.5 & 0.886 \\
\hline & Landscape $\times$ distance & 12 & 594 & 3.0 & 0.009 \\
\hline \multirow[t]{7}{*}{ Grass $10-30 \mathrm{~cm}$} & Intercept & 1 & 594 & 295.9 & $<0.001$ \\
\hline & Season & 1 & 594 & 1.1 & 0.306 \\
\hline & Landscape & 1 & 594 & 3.2 & 0.072 \\
\hline & Distance & 12 & 594 & 2.4 & 0.005 \\
\hline & Season $\times$ landscape & 1 & 594 & 0.1 & 0.775 \\
\hline & Season $\times$ distance & 12 & 594 & 0.8 & 0.644 \\
\hline & Landscape $\times$ distance & 12 & 594 & 1.2 & 0.315 \\
\hline \multirow[t]{7}{*}{ Grass $>30 \mathrm{~cm}$} & Intercept & 1 & 594 & 378.4 & $<0.001$ \\
\hline & Season & 1 & 594 & 37.5 & $<0.001$ \\
\hline & Landscape & 1 & 594 & 60.9 & $<0.001$ \\
\hline & Distance & 12 & 594 & 3.6 & 0.002 \\
\hline & Season $\times$ landscape & 1 & 594 & 0.1 & 0.782 \\
\hline & Season $\times$ distance & 12 & 594 & 0.6 & 0.862 \\
\hline & Landscape $\times$ distance & 12 & 594 & 2.7 & 0.001 \\
\hline \multirow[t]{7}{*}{ Forbs } & Intercept & 1 & 594 & 583.6 & $<0.001$ \\
\hline & Season & 1 & 594 & 7.4 & 0.007 \\
\hline & Landscape & 1 & 594 & 0.5 & 0.475 \\
\hline & Distance & 12 & 594 & 5.0 & $<0.001$ \\
\hline & Season $\times$ landscape & 1 & 594 & 0.1 & 0.755 \\
\hline & Season $\times$ distance & 12 & 594 & 0.5 & 0.897 \\
\hline & Landscape $\times$ distance & 12 & 594 & 0.3 & 0.988 \\
\hline \multirow[t]{7}{*}{ Shrubs } & Intercept & 1 & 594 & 195.3 & $<0.001$ \\
\hline & Season & 1 & 594 & 0.2 & 0.639 \\
\hline & Landscape & 1 & 594 & 7.0 & 0.009 \\
\hline & Distance & 12 & 594 & 5.4 & $<0.001$ \\
\hline & Season $\times$ landscape & 1 & 594 & 0.0 & 0.884 \\
\hline & Season $\times$ distance & 12 & 594 & 0.3 & 0.992 \\
\hline & Landscape $\times$ distance & 12 & 594 & 1.0 & 0.469 \\
\hline
\end{tabular}

water and to the short and nutritious grass swards maintained by hippos exert additional impacts on vegetation structure and basal cover in the piosphere gradients originating from rivers (Butt et al. 2009; Ogutu et al. 2010). Piosphere gradients were not clearly discernible in the pastoral ranches, possibly due to the intense and homogenizing effects of livestock grazing (Fig. 3; Adler et al. 2001). Hippos extended their grazing range further from water points in dry seasons, likely due to forage depletion near water as the dry season progresses (O'Connor and Campbell 1986), but this seasonal range expansion was more constrained in the pastoral areas, where herders 
Table 2 Results of statistical tests of the effects of season, landscape, distance from water, and their interactions on the density of herbivore dung piles in the Mara region of Kenya

\begin{tabular}{lrrrrr}
\hline Effects & NDF & DDF & \multicolumn{1}{l}{ MS } & \multicolumn{1}{l}{$F$} & $P>F$ \\
\hline Intercept & 1 & 596 & 71.84 & 200.90 & $<0.001$ \\
Season & 1 & 596 & 10.54 & 29.49 & $<0.001$ \\
Landscape & 1 & 596 & 2.93 & 8.18 & 0.004 \\
Distance & 12 & 596 & 0.33 & 0.92 & 0.523 \\
Season $\times$ landscape & 1 & 596 & 1.53 & 4.29 & 0.039 \\
Season $\times$ distance & 12 & 596 & 0.31 & 0.87 & 0.582 \\
Landscape $\times$ distance & 12 & 596 & 0.13 & 0.36 & 0.977 \\
\hline
\end{tabular}

$N D F$ is the degrees of freedom of the numerator and $D D F$ is degrees of freedom of the denominator

Table 3 Results of statistical tests of the effects of season, landscape, distance from water, and their interactions on aggregate herbivore biomass in the Mara Region of Kenya

\begin{tabular}{lrrrrr}
\hline Effect & NDF & DDF & \multicolumn{1}{l}{ MS } & \multicolumn{1}{l}{$F$} & $P>F$ \\
\hline Intercept & 1 & 596 & $4,998.00$ & 270.81 & $<0.001$ \\
Season & 1 & 596 & 451.30 & 24.45 & $<0.001$ \\
Landscape & 1 & 596 & 172.69 & 9.36 & 0.002 \\
Distance & 12 & 596 & 66.45 & 3.60 & $<0.001$ \\
Season $\times$ landscape & 1 & 596 & 34.56 & 1.87 & 0.172 \\
Season $\times$ distance & 12 & 596 & 26.49 & 1.44 & 0.145 \\
Landscape $\times$ distance & 12 & 596 & 50.66 & 2.74 & 0.001 \\
\hline
\end{tabular}

$N D F$ is the degrees of freedom of the numerator and $D D F$ is degrees of freedom of the denominator

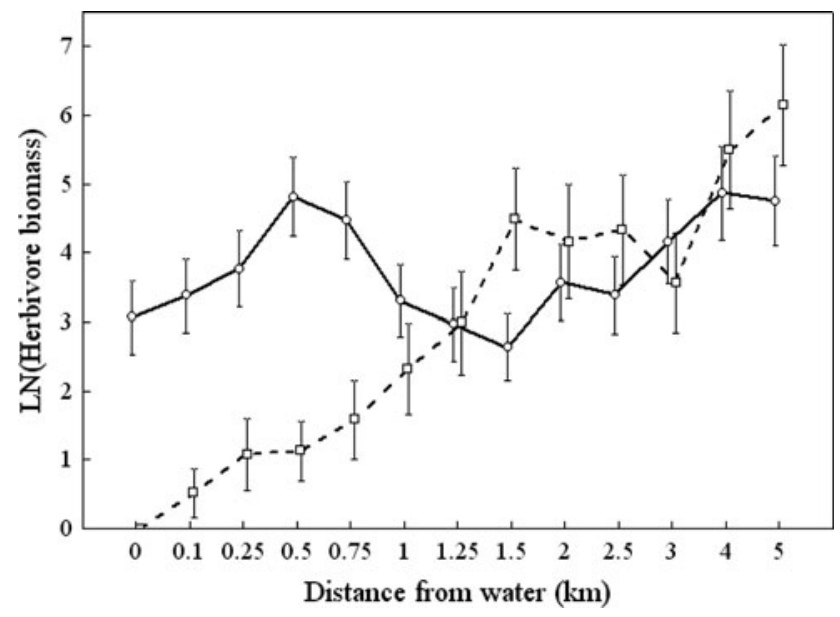

Fig. 4 The distribution of herbivore biomass as a function of distance from water in the Mara region of Kenya during 2007-2008. Solid and dashed lines denote the Masai Mara National Reserve and pastoral ranches, respectively

graze livestock along rivers in dry seasons, thus depleting vegetation and interfering with the hippo ranging pattern from water (Belsky et al. 1999; Thrash 2000). An earlier
Table 4 Results of statistical tests of the effects of season, landscape, distance from water, and their interactions on large herbivore species richness in the Mara region of Kenya

\begin{tabular}{lrrrrr}
\hline Effect & NDF & DDF & MS & $F$ & $P>F$ \\
\hline Intercept & 1 & 596 & 544.39 & $3,347.31$ & $<0.001$ \\
Season & 1 & 596 & 4.67 & 28.7 & $<0.001$ \\
Landscape & 1 & 596 & 0.66 & 4.04 & 0.044 \\
Distance & 12 & 596 & 0.57 & 3.53 & $<0.001$ \\
Season $\times$ landscape & 1 & 596 & 0.06 & 0.35 & 0.553 \\
Season $\times$ distance & 12 & 596 & 0.27 & 1.68 & 0.068 \\
Landscape $\times$ distance & 12 & 596 & 0.49 & 3.01 & $<0.001$ \\
\hline
\end{tabular}

$N D F$ is the degrees of freedom of the numerator and $D D F$ is degrees of freedom of the denominator

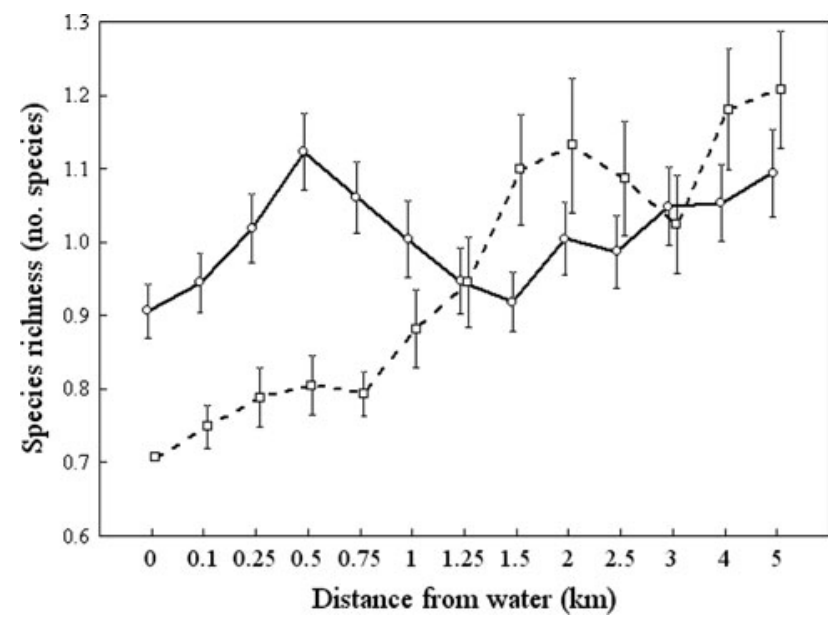

Fig. 5 The distribution of large herbivore species richness (number of different species) as a function of distance from water in the Mara region of Kenya during 2007-2008. Solid and dashed lines denote the Masai Mara National Reserve and pastoral ranches, respectively

record of the hippo grazing range along the Mara River north of the SNP in the 1970s, of $1.5 \mathrm{~km}$ (Olivier and Laurie 1974), was smaller than the present estimate of $4 \mathrm{~km}$, suggesting that the recent dramatic increase in the population of Mara hippos (Kanga et al. 2011) or the progressive compression of the hippo distribution, due to changing land use over the last three decades and competition with livestock and other herbivores along the riparian-edge habitats (Reid et al. 2003), probably compel hippos to travel further from water to satisfy their forage requirements.

Unlike in the pastoral ranches, a sacrificial zone with heavily depleted grass cover due to repeated grazing and trampling by hippos leaving and returning to water (Thrash and Derry 1999) was well established in the MMNR and extended for about $250 \mathrm{~m}$ from river banks. This area was characteristically denuded, had the highest number of hippo trails, and the highest percent cover of short grasses and forbs. However, the pastoral ranches had a higher 
percent cover of bare ground than the MMNR beyond $750 \mathrm{~m}$ from water, which can be attributed to the impacts of heavy grazing and trampling by large numbers of livestock (Fig. 3a). Therefore, differences in their grazing strategies may explain the contrasting impacts of hippo and livestock grazing on patterns of variation in vegetation structure and cover along gradients extending away from riparian habitats in the Mara. We found that close to water, grass was very short in both landscapes, and that this short grass cover declined progressively with increasing distance from water in the MMNR but remained high in the pastoral areas up to $5 \mathrm{~km}$ from water, thus signifying the effects of heavy livestock grazing in the pastoral ranches. The shifting mosaics of short grass lawns interspersed with patches of medium and tall grasses were characteristically evident within $2.5 \mathrm{~km}$ of water in the MMNR, and can be attributed to hippo grazing, as this distance corresponds to the active grazing range of hippos from water. These mosaics of short grass lawns are well recognized for their high-quality forage (McNaughton 1983; Fryxell 1991; Adler et al. 2001; Olff et al. 2002). In contrast, vegetation cover in the pastoral ranches was dominated by homogeneous short grasses, often shorter than $10 \mathrm{~cm}$, associated with intense and sustained livestock grazing (Fig. 3c). Although grazing kept grass height relatively low, grasses still constituted the main fraction of herbaceous cover.

Spatial heterogeneity of vegetation increases with patch grazing and decreases with homogeneous grazing (Adler et al. 2001), and it influences how herbivores utilize landscapes, especially in areas where forage and water availability are major limiting factors, such as the Masai Mara. Our results show that herbivore dung, biomass and species richness were significantly higher during the dry than the wet season, implying that forage and water are more heavily utilized during dry seasons in the Mara. Furthermore, herbivores utilized the MMNR more during the dry season, because they are excluded from the pastoral areas by heavy livestock grazing at this time, and because of the influx of enormous herds of migratory wildebeest, zebra, and Thomson's gazelles. Herbivore biomass and species richness were higher in the MMNR than the pastoral areas, with quadratic distribution patterns from water apparent in the MMNR and linear patterns evident in the ranches (Figs. 4, 5), implying that herbivores were more repelled from water points in the pastoral ranches. We postulate that the effects of shifting mosaics of grazing lawns maintained by hippos improve the quality of available forage close to water, which attracts herbivores in the MMNR riparian-edge habitats (McNaughton 1983; OwenSmith 1988; Fryxell 1991; Eltringham 1999; Adler et al. 2001; Olff et al. 2002; Arsenault and Owen-Smith 2002; Verweij et al. 2006; Van Wieren and Bakker 2008). In contrast, the intense and homogeneous livestock grazing in the pastoral ranches limits forage intake by herbivores (Arsenault and Owen-Smith 2002; Verweij et al. 2006), and repels herbivores from water points. Ultimately, continued sedentarization of pastoralists in the Mara region will progressively exclude herbivores and other wildlife from the pastoral areas of the Mara, similar to patterns reported for other parts of Masailand (Western et al. 2009; Msoffe et al. 2011).

High vegetation cover limits the ability of herbivores to scan their surroundings, but also provides good concealment cover for ambush predators (Hopcraft 2002; Verdolin 2006; Hopcraft et al. 2010). Our results demonstrate that herbivores were more abundant in areas of short to medium grass swards than in areas dominated by tall grasses (associated with higher predation risks). This may imply that herbivores were avoiding areas of tall grasses because these areas are of lower forage quality and because of the increased risks of predation. Specifically, predation risk was lower in areas dominated by grasses shorter than $30 \mathrm{~cm}$ but higher in areas dominated by tall grasses, implying that areas with mosaics of short grass lawns maintained by hippo grazing likely reduced predation risk. Therefore, loss of keystone species like hippopotamus may adversely impact the integrity of ecosystems and their services (Coppollilo et al. 2004)

Hippopotamus and other herbivores are apparently able to spread the impacts of their grazing in the MMNR and sustain characteristic distribution patterns of vegetation structure and cover, enabling them to access more forage resources through the dry season (Arsenault and OwenSmith 2002). This could explain the higher herbivore biomass and species richness we recorded in the MMNR. In contrast, the pastoral ranches experience year-round intense livestock grazing, resulting in homogeneous short grasslands, thus amplifying competition for forage and water in areas accessed by pastoralists (including parts of the MMNR), especially during dry periods.

The grazing gradients from riparian-edge habitats in the MMNR revealed by this study are consistent with the findings of other studies conducted elsewhere in piospheres (Andrew 1988; Perkins and Thomas 1993; Thrash and Derry 1999), but were hardly evident in the pastoral ranches. Our results thus demonstrate conspicuous differences in the effects of hippopotamus and livestock grazing, with hippo grazing enhancing spatial heterogeneity, which attracts a richer herbivore assemblage, whereas livestock grazing homogenizes landscapes and repels many species of wild herbivores, especially from water sources.

Acknowledgments We thank Charles Matankory and Sospeter Kiambi for assistance with the field work and for arranging field logistics. We also thank the Kenya Wildlife Service rangers for providing security during field work, and wardens of the Masai Mara Reserve and the management of the Koyiaki and Lemek pastoral 
ranches for allowing us unlimited access to the study area. EK was supported by the Netherlands Fellowship Program (NFP) and the University of Groningen through the Government of Kenya, and by the Frankfurt Zoological Society (FZS).

Open Access This article is distributed under the terms of the Creative Commons Attribution Noncommercial License which permits any noncommercial use, distribution, and reproduction in any medium, provided the original author(s) and source are credited.

\section{References}

Adler PB, Raff DA, Lauenroth WK (2001) The effect of grazing on the spatial heterogeneity of vegetation. Oecologia 128:465-479

Andrew MH (1988) Grazing impacts in relation to livestock watering points. Trends Ecol Evol 3:336-339

Arsenault R, Owen-Smith N (2002) Facilitation versus competition in grazing herbivore assemblages. Oikos 97:313-318

Bailey DW, Gross JE, Laca EA, Rittenhouse LR, Coughenour MB, Swift DM, Sims PL (1996) Mechanisms that result in large herbivore grazing distribution patterns. J Range Manage 49:386-400

Belsky AJ, Matzke A, Uselman S (1999) Survey of livestock influences on stream and riparian ecosystems in the Western United States. J Soil Water Conserv 54:419-431

Bergman CM, Fryxell JM, Gates CC, Fortin D (2001) Ungulate foraging strategies: energy maximizing or time minimizing? J Anim Ecol 70:289-300

Boutton TW, Tieszen LL, Imbamba SK (1988) Biomass dynamics of grassland vegetation in Kenya. Afr J Ecol 26:89-101

Butt B, Shortridge A, WinklerPrins AMGA (2009) Pastoral herd management, drought coping strategies, and cattle mobility in southern Kenya. Ann Assoc Am Geogr 99:309-334

Coe MJ, Cumming DH, Philipson J (1976) Biomass and production of large African herbivores in relation to rainfall and primary production. Oecologia 22:341-354

Coppollilo P, Gomez H, Maisels F, Wallace R (2004) Selection criteria for suites of landscape species as a basis for site-based conservation. Biol Conserv 115:419-430

Coughenour MB (1991) Spatial components of plant-herbivore interactions in pastoral, ranching and native ungulate ecosystems. J Range Manage 44:530-542

Demment MW, Vansoet PJA (1985) Nutritional explanation for bodysize patterns of ruminant and nonruminant herbivores. Am Nat 125:641-672

Deshmukh IK (1984) A common relationship between precipitation and grassland peak biomass for east and southern Africa. Afr J Ecol 22:181-186

Eltringham SK (1999) The hippos: natural history and conservation. Academic, London

Epp H, Agatsiva J (1980) Habitat types of the Mara-Narok area, western Kenya (unpublished report, series no. 20). Department of Resource Surveys and Remote Sensing, Nairobi

Fleischner TL (1994) Ecological costs of livestock grazing in Western North America. Conserv Biol 8:629-644

Fryxell J (1991) Forage quality and aggregation by large herbivores. Am Nat 138:478-498

Fryxell JM, Sinclair ARE (1988) Seasonal migration by white-eared kob in relation to resources. Afr J Ecol 26:17-31

Fryxell JM, Greever J, Sinclair ARE (1988) Why are migratory ungulates so abundant? Am Nat 131:781-798

Hernandez L, Laundre JW (2005) Foraging in the "landscape of fear" and its implications for habitat use and diet quality of elk Cervus elaphus and bison Bison bison. Wildl Biol 11:215-220
Hobbs NT (1996) Modification of ecosystems by ungulates. J Wildl Manage 60:2397-2402

Homewood K, Lambin EF, Coast E, Kariuki A, Kikula I, Kivelia J, Said M, Serneels S, Thompson M (2001) Long-term changes in Mara-Serengeti wildlife and land cover: pastoralists, population or policies? Nat Acad Sci Proc 98:2544-12549

Hopcraft G (2002) The role of habitat and prey density on foraging by Serengeti Lions (dissertation). University of British Columbia, Vancouver

Hopcraft JGC, Olff H, Sinclair ARE (2010) Herbivores, resources and risks: alternating regulation along primary environmental gradients in savannas. Trends Ecol Evol 25:119-128

Illius AW, O'Connor TG (2000) Resource heterogeneity and ungulate population dynamics. Oikos 89:283-294

James CD, Landsberg J, Morton SR (1999) Provision of watering points in the Australian arid zone: a review of effects on biota. J Arid Environ 41:87-121

Jarman PJ (1974) Social-organization of antelopes in relation to their ecology. Behaviour 48:215-266

Jones KB (1981) Effects of grazing on lizards' abundance and diversity in western Arizona. Southwest Nat 26:107-115

Kanga EM, Ogutu JO, Olff H, Santema P (2011) Population trend and distribution of the vulnerable common hippopotamus (Hippopotamus amphibius) in the Mara Region of Kenya. Oryx 45:20-27

Kimani K, Pickard J (1998) Recent trends and implications of group ranch subdivision and fragmentation in Kajiado District, Kenya. Geogr J 164:202-213

Lamprey RH, Reid RS (2004) Expansion of human settlement in Kenya's Maasai Mara: what future for pastoralism and wildlife? J Biogeogr 31:997-1032

Landsberg J, James CD, Morton SR, Muller WJ, Stol J (2003) Abundance and composition of plant species along grazing gradients in Australian rangelands. J Appl Ecol 40:1008-1024

Lange RT (1969) The piosphere, sheep track and dung pattern. J Range Manage 22:396-400

Lock JM (1972) The effects of hippopotamus grazing on grasslands. J Ecol 60:445-467

Mati BM, Mutie S, Gadain H, Home P, Mtalo F (2008) Impacts of land-use/cover changes on the hydrology of the transboundary Mara River, Kenya/Tanzania. Lakes Reserv Res Manage 13:169-177

McNaughton SJ (1983) Serengeti grassland ecology: the role of composite environmental factors and contingency in community organization. Ecol Monogr 53:291-320

Milchunas DG, Laurenroth WK (1993) Quantitative effects of grazing on vegetation and soil cover over a global range of environments. Ecol Monogr 63:327-366

Msoffe FU, Kifugo SC, Said MY, Neselle M, Gardingen P, Reid RS, Ogutu JO, Herero M, Leeuw J (2011) Drivers and impacts of land-use change in the Maasai Steppe of northern Tanzania: an ecological, social and political analysis. J Land Use Sci. doi: 10.1080/1747423X.2010.511682

Murray MG, Illius AW (2000) Vegetation modification and resource competition in ungulates. Oikos 89:501-508

O'Connor TG, Campbell BM (1986) Hippopotamus habitat relationships on the Lundi River, Gonarezhou National Park, Zimbabwe. Afr J Ecol 24:7-26

Oba G, Post E, Syvertsen PO, Stenseth NC (2000) Bush cover and range condition assessments in relation to landscape and grazing in southern Ethiopia. Landscape Ecol 15:535-546

Ogutu JO, Owen-Smith N, Piepho H-P, Said MY (2011) Continuing wildlife population declines and range contraction in the Mara region of Kenya during 1977-2009. J Zool (in press)

Ogutu JO, Piepho HP, Dublin HT, Bhola N, Reid RS (2007) El Ninosouthern oscillation, rainfall, temperature and normalized 
difference vegetation fluctuations in the Mara-Serengeti ecosystem. Afr J Ecol 46:132-143

Ogutu JO, Piepho H-P, Reid RS, Rainy ME, Kruska RL, Worden JS, Nyabenge M, Hobbs NT (2010) Large herbivore responses to water and settlements in savannas. Ecol Monogr 80:241-266

Olff H, Ritchie ME, Prins HHT (2002) Global environmental controls of diversity in large herbivores. Nature 415:901-904

Olivier RCD, Laurie WA (1974) Habitat utilization by hippopotamus in the Mara River. E Afr Wildl J 12:249-271

Owen-Smith RN (1988) Megaherbivores: the influence of very large body size on ecology. Cambridge University Press, Cambridge

Perkins JS, Thomas DSG (1993) Environmental responses and sensitivity to permanent cattle ranching in semi-arid western central Botswana. In: Thomas DSG, Alison RJ (eds) Landscape sensitivity. Wiley, Chichester, pp 273-286

Pienaar U de V, Van-Wyk P, Fairall N (1966) An experimental cropping scheme of hippopotami in the Letaba River of the Kruger National Park. Koedoe 9:1-33

Prins HHT (2000) Competition between wildlife and livestock in Africa. In: Prins HHT, Grootenhuis JG, Dolan TT (eds) Wildlife conservation by sustainable use. Kluwer, Dordrecht, pp 51-80

Prins HHT, Olff H (1998) Species-richness of African grazer assemblages: towards a functional explanation. In: Newbery DM, Prins HHT, Brown ND (eds) Dynamics of tropical communities. Blackwell, Oxford, pp 449-489

Quinn MA, Walgenbach DD (1990) Influence of grazing history on the community structure of grasshoppers of a mixed grass prairie. Environ Entomol 9:1756-1766

Redfern JV, Grant CC, Biggs HC, Getz WM (2003) Surface water constraints on herbivores foraging in the Kruger National Park. S Afr J Ecol 84:2092-2107

Reid RS, Rainy M, Ogutu J, Kruska RL, Kimani K, Nyabenge M, McCartney M, Kshatriya M, Worden J, Ng'ang'a L, Owuor J, Kinoti J, Njuguna E, Wilson CJ, Lamprey R (2003) Mara Count 2002: people, wildlife and livestock in the Mara ecosystem: the Mara Count 2002 (unpublished report). International Livestock Research Institute, Nairobi

Ruppert D, Ward MP, Carroll RJ (2003) Semiparametric regression. Cambridge University Press, Cambridge

SAS Institute Inc. (2009) SAS system for windows, version 9.1.3. SAS Institute Inc., Cary

Serneels S, Said MY, Lambin EF (2001) Impact of land use changes on the wildebeest migration in the northern part of the SerengetiMara ecosystem. J Biogeogr 28:391-407
Sinclair ARE, Arcese P (1995) Serengeti in the context of worldwide conservation efforts. In: Sinclair ARE, Arcese P (eds) Serengeti II: dynamics, management, and conservation of an ecosystem. University of Chicago Press, Chicago, pp 31-46

Skarpe C (1991) Impact of grazing in Savannah ecosystems. Ambio 20:351-356

StatSoft Inc. (2007) STATISTICA (data analysis software system), version 8.0. http://www.statsoft.com

Thornton DD (1971) The effect of complete removal of hippopotamus on grasslands in the Queen Elizabeth National Park, Uganda. E Afr Wildl J 9:47-53

Thrash I (1998) Impact of large herbivores at artificial watering compared to that at natural watering points in Kruger National Park, South Africa. J Arid Environ 38:315-324

Thrash I, Derry JF (1999) The nature and modeling of piospheres: a review. Koedoe 42:73-94

Thrash I (2000) Determinants of the extent of indigenous large herbivore impact on herbaceous vegetation at watering points in the north-eastern lowveld, South Africa. J Arid Environ 44:61-72

Van Wieren SE, Bakker JP (2008) The impacts of browsing and grazing herbivores on biodiversity. In: Gordon J, Prins HHT (eds) The ecology of browsing and grazing (Ecol Stud 195). Springer, Berlin, pp 263-292

Vavra M (2005) Livestock grazing and wildlife: developing compatibilities. Range Ecol Manage 58:128-134

Verdolin JL (2006) Meta-analysis of foraging and predation risk tradeoffs in terrestrial systems. Behav Ecol Sociobiol 60:457-464

Verlinden A (1997) Human settlement and wildlife distribution in the southern Kalahari of Botswana. Biol Conserv 82:129-136

Verweij RJT, Verrelst J, Loth PE, Heitkonig IMA, Brunsting AMH (2006) Grazing lawns contribute to the subsistence of mesoherbivores on dystrophic savannas. Oikos 114:108-116

Western D (1975) Water availability and its influence on the structure and dynamics of a savannah large mammal community. E Afr Wildl J 13:265-286

Western D, Groom R, Worden J (2009) The impact of subdivision and sedentarization of pastoral lands on wildlife in an African savanna ecosystem. Biol Conserv 142:2538-2546

Wilmshurst JF, Fryxell IF, Bergman CM (2000) The allometry of patch selection in ruminants. Proc R Soc Lond B Biol Sci 267: 345-349 